\title{
Design of an Interactive Cellular System for the Remote Operation of Ocean Sensors: A Pilot Study Integrating Radioactivity Sensors
}

\author{
Stylianos Alexakis and Christos Tsabaris * D
}

check for updates

Citation: Alexakis, S.; Tsabaris, C. Design of an Interactive Cellular System for the Remote Operation of Ocean Sensors: A Pilot Study Integrating Radioactivity Sensors. J. Mar. Sci. Eng. 2021, 9, 910.

https://doi.org/10.3390/jmse9080910

Academic Editor: Rafael Morales

Received: 12 July 2021

Accepted: 19 August 2021

Published: 22 August 2021

Publisher's Note: MDPI stays neutral with regard to jurisdictional claims in published maps and institutional affiliations.

Copyright: (c) 2021 by the authors. Licensee MDPI, Basel, Switzerland. This article is an open access article distributed under the terms and conditions of the Creative Commons Attribution (CC BY) license (https:/ / creativecommons.org/licenses/by/ $4.0 /)$.
Hellenic Center for Marine Research, Institute of Oceanography, $46.7 \mathrm{Km}$ Athens-Sounio Ave, 19013 Anavyssos, Greece; salexakis@hcmr.gr

* Correspondence: tsabaris@hcmr.gr; Tel.: +30-2291076410

\begin{abstract}
Ocean in-situ sensors are crucial for measuring oceanic parameters directly from the sea in a spatial and temporal basis. Real-time operation is used in many applications related to decision support tools and early warning services in case of accidents, incidents and/or disasters. The design of the proposed system is described as a rapid-response detection system, which aims to measure natural and artificial radioactive contaminants or other crucial ocean parameters, to replace the traditional method of sampling. The development of an interactive cellular system is undertaken using a commercial router that is programmed according to sensor specifications. A radioactivity sensor is integrated in a communication box enabling self-powered operation with a solar panel. The proposed system operates in (near) real-time mode and provides gamma-ray spectra by integrating the sensor and the appropriate electronic modules in it. Additionally, an on-site experiment was conducted to test the operability of the system in a real environment close to the sea, for monitoring fallout due to rainfall and snowfall events. The main intense radionuclides that were observed by different energy lines, were radon progenies $\left({ }^{214} \mathrm{Bi},{ }^{214} \mathrm{~Pb}\right)$. The continuous operation of the whole system was controlled by operating the system during the winter period.
\end{abstract}

Keywords: telemetry; ocean sensors; radioactivity; real-time transmission

\section{Introduction}

Telemetry is a method that refers to the acquisition and automatic transmission of in-situ or remote data, enabling suitable sensors for monitoring purposes. The acquired data in most cases may be accessed by the end users via the Internet, and the data transmission is made via telephone networks, satellite or RF methods. The development of satellite, RF, and cellphone telemetry technologies has made oceanographic applications very practical. Ocean observing systems provide continuous data of physical, biological, chemical, and geological parameters in the seawater column as well as at the ocean floor. The long-term data provide information of sea variability and capture potential incidences of accidents [1,2]. Furthermore, ocean observing systems provide real-time data and thus are useful to monitor phenomena of natural hazards (e.g., earthquakes, tsunamis, volcanoes), to study climate change variability, and to collect biogeochemical parameters for seawater and sediment. Moreover, real-time ocean observing systems support the study of ecosystems, fisheries and water quality and also provide data for long-term ecosystem functioning and support improvements of decision tools.

As concerns marine radioactivity monitoring needs due to Nuclear Power Plant (NPP) operation, there are 55 reactors under construction and 450 in operation worldwide [3]. Furthermore, some countries build their own floating NPP that can be transferred to coastal areas or open sea to provide electricity [4]. Therefore, there is a need for methods to perform routine monitoring to quantify the radioactivity level near power plants, to evaluate potential hazards due to plume leaks into the ocean, and/or due to the disposal of nuclear waste products, and/or due to nuclear accidents (e.g., Fukushima Dai-ichi NPP) [5]. 
In case of accident, radioactive plumes can spread all over the world through ocean currents (for long-lived radioisotopes), affecting marine life and subsequently humans through the food chain [6-10]. The key radionuclide sources generated by normal operation of a nuclear power plant are fission and activation products, some of which can be detected and monitored by gamma-ray spectrometers. These artificial radionuclides are released during reactor's operation or when spent fuel from the reactor is processed [11]. The operation of NPPs near coastal areas may affect the health of the neighboring aquatic system directly by releasing radioactive substances. In order to monitor the pathways of released radionuclides into coastal zones in a spatial and temporal manner, it is necessary to set up smart and effective detection systems that can be deployed in selected areas, and/or integrated in existing marine fixed and mobile stations. The selected areas and pathways to which in-situ measurement would be applied are defined using hydrodynamic models that simulate ocean circulation predicting the pathways of radionuclides [12].

Real-time ocean observing systems require remote communication technologies (e.g., satellite, RF, and cellphone telemetry). As concerns cellular telemetry, it is based on the wireless transmission of data, which can be accessed via the Internet since data transmissions are made from areas where a cellular signal is present. To this end, a typical series cellular router is set up to provide large data transfers using public networks. It transparently connects one device to a cellular network, allowing the user to connect to existing devices $[13,14]$.

The radioactivity in-situ subsea systems can be integrated in the developed communication box (consisting of a sensor, a battery pack, a router and a solar panel) for continuous monitoring of radioactivity using the (near) real-time method. Communication methods are interactive between the operational center and the communication box, the specifications of which allow it to be easily integrated into buoys or other fixed stations. The data loggers of most buoys cannot host many ocean sensors due to power consumption issues and/or due to incompatible specifications. These obstacles may be overcome using the proposed communication system as a "plug-and-play" configuration. Another advantage of the newly developed system is that it is cost-effective and operates in an autonomous way in terms of power. The in-situ radioactivity sensor GeoMAREA [14] also has the advantage of separating different sources of artificial radioactivity, and thus can be suitable to early warning applications for inspection issues, or to perform surveys in ports where the ballast waters of vessels from other countries may create a contamination hazard. The communication box has a modular configuration for the integration of three other sensors (two with a serial port and two with Ethernet communication protocols). However, the pilot study was performed by integrating the medium resolution spectrometer GeoMAREA [14] into the communication box.

First, the presentation of the cellular system is described, together with the integrated sensors. A detailed description is given of the structure of the software development for the data transmission and data management. The system is tested for a specific period of time, and the data are discussed according to gradients of activity concentration of natural radionuclides (e.g., snowfall). The future applications of the system are also given.

\section{Materials and Methods}

\subsection{The Communication Box}

The communication box used consisted of an integrated sensor, a router, a photovoltaic module and appropriate battery packs. These units are described below.

F3826 Series router is a cellular terminal module that enables the transfer of large amounts of data by public networks (such as GPRS, CDMA, WCDMA, EVDO, LTE). The router enables an industrial 32-bits CPU and an embedded real-time operating system supporting RS232 (or RS485/RS422) communication ports and Ethernet protocols, where the module of interest may be connected to a cellular network. Such connection allows any end-user to interact with the connected module through the serial and Ethernet communication modes. Last year's cellular devices have been widely used on M2M (machine to machine) communication. 
As concerns environmental applications, such routers are used for industrial automation processes, water supply and environmental protection issues though the development and application of decision support and alarm systems.

The router may host (integrate) one sensor with one serial RS232 output and two sensors operating with Ethernet ports. The router, via the SIM card, provides connection to the Internet through the Internet service provider (ISP). The router can be configured to act like a client using TCP sockets, and to connect to specific server software implemented at HCMR data center. After a connection is established, the commands are forwarded to the serial port from and to the sensors, and the end-user operates the system (e.g., start, stop, and retrieve data). After the establishment of the connection, the serial port may be accessed remotely by sending and receiving the appropriate commands. In fact, the control of the integrated sensor is achieved in the same manner, as the detection system is operated using a cabled connection with the computer system once socket-based communication has been established.

The router was selected to conveniently and transparently connect a device to a cellular network enabling the basic configuration. The use of RS232 communication was decided since most of the ocean sensors support RS232 communication protocols. Furthermore, the selection of RS232 protocol was proposed to optimize the system operation for greater depths where long underwater data cables are required. The communication box and its connections are depicted in Figure 1.

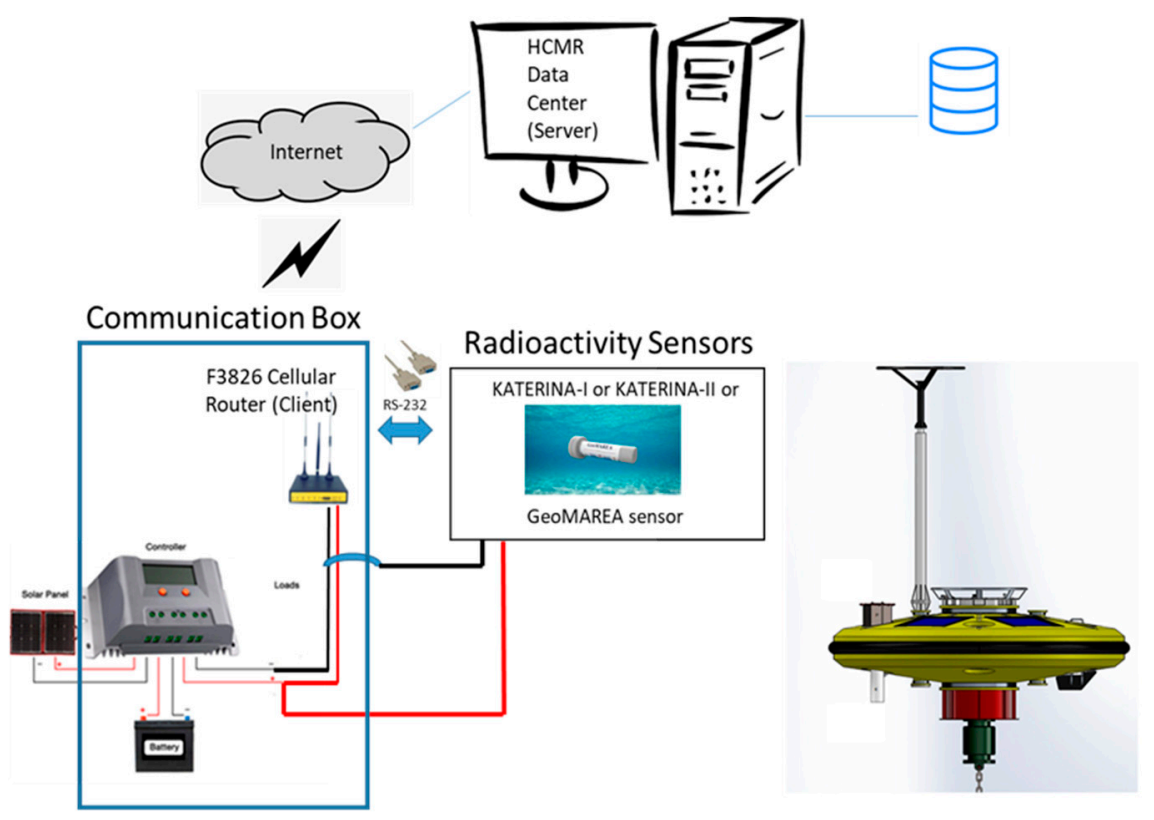

Figure 1. Schematic connections of the communication system, integrated sensor and platforms.

In our system a 12 Volts-30 Watt photovoltaic panel was used to charge the battery of the system from solar energy. It is a monocrystalline module with aluminum chassis with dimensions $360 \times 540 \times 25 \mathrm{~mm}$. Its weight is $3 \mathrm{~kg}$. It is composed of 36 cells in series. The charge controller used was an MPPT 12 Volts 10 Amperes digital charge controller with $99.9 \%$ tracking efficiency and $97 \%$ conversion efficiency. As concerns the power of the system, only an AGM battery with a capacity of $42 \mathrm{Ah}$ was connected to the controller of the photovoltaic module.

The loads connected to the communication box were the GeoMAREA and KATERINA sensors as well as the cellular router. In the applied task, the F3826 cellular router was used, connecting via RS-232 port the KATERINA-I and II as well as the GeoMAREA detection systems to obtain remotely acquired gamma-ray spectra to the operational center, using data transfer protocols of existing public cellular networks. 


\subsection{Sensors and Calibration}

Three submarine spectrometers were utilized for integration purposes to provide gammaray spectra at the area of deployment on a continuous basis. The low resolution 3 " $\times 3$ " $\mathrm{NaI}(\mathrm{Tl})$ scintillation detector KATERINA I and II [13] and the new medium resolution CeBr3 detector with 2" $\times 2$ "dimentions (named GeoMAREA) [14] were used for continuous monitoring at the two areas of study. The operating characteristics of the systems include the adjustable energy range $50-3000 \mathrm{keV}$, typical for environmental applications, an operating temperature range from $-5^{\circ} \mathrm{C}$ to $+50{ }^{\circ} \mathrm{C}$, a maximum operational depth up to $400 \mathrm{~m}$, low and continuously controlled power consumption $(\sim 2.5 \mathrm{~W}$ for KATERINA I, $\sim 1 \mathrm{~W}$ for KATERINA II and $0.8 \mathrm{~W}$ for GeoMAREA, respectively) and waterproof enclosure of acetal for minimum attenuation of gamma-rays. The data logger of the GeoMAREA system has the option to use different communication protocols (e.g., USB, RS-232 and Ethernet). In our case, the connection was made via the RS-232 communication protocol.

The sensors were calibrated (for energy, energy resolution and efficiency) for aquatic deployments by deploying them in a laboratory tank of $5.5 \mathrm{~m}^{3}$ filled with freshwater using standard calibration sources of radionuclides, while the results were reproduced and further extended in the operational energy range by numerical Monte Carlo simulations [14-17]. Indicatively, the energy resolution at the energy of $661.6 \mathrm{keV}\left({ }^{137} \mathrm{Cs}\right.$ photopeak) is $6.5-6.8 \%$ for the KATERINA I and II detectors and 3.5-3.7\% for the GeoMAREA system, respectively. The systems were applied in direct-connection or stand-alone mode to a variety of marine applications in stationary and mobile platforms [18-23].

During the first period (October 2020 to December 2020), the time lag of the system was set to $3592 \mathrm{~s}$ according to the suggestion $(\sim 1 \mathrm{~h})$ of fixed station protocol at sea. Due to the acquired radionuclides the time lag of the detection system during the second period was defined as $1192 \mathrm{~s}$ for detecting mainly radon concentrations (due to the half-life of the radon daughters).

\subsection{Algorithm Description}

The server software at HCMR's data center detects for incoming connections at a specific port. The loop process follows simplified concepts; the flowchart of the algorithm is depicted in Figure 2. The computer, which acts as the server at HCMR data center, must be switched on at all times. In case of power failure, the server will shut down. On the next power-up the server's software-after a socket connection has been established-needs to stop the sensor and clear the spectrum from the sensor's memory buffer. Following this, the timer loop is started with an acquisition period of $3600 \mathrm{~s}$. The first task inside the timer loop is to enable the acquisition by sending the "Enable Acquisition" command. The server's software needs to "sleep" for $3592 \mathrm{~s}$ to finalize the measurement of the sensor. After the end of the measurement (when acquisition has been completed), the next task is to request the spectrum from the sensor by sending the "Request Spectrum" command. The last task of the timer loop is to clear the spectrum (using the command "Clear Spectrum") from the sensor's memory buffer and then return to the start line. The $8 \mathrm{~s}$ period (3600-3592) is the time needed for the data to be transferred through TCP/IP sockets to the server. The sensor's preset time was set to $3592 \mathrm{~s}$ in the first installation since the total duration of the timer loop is $3600 \mathrm{~s}$. 


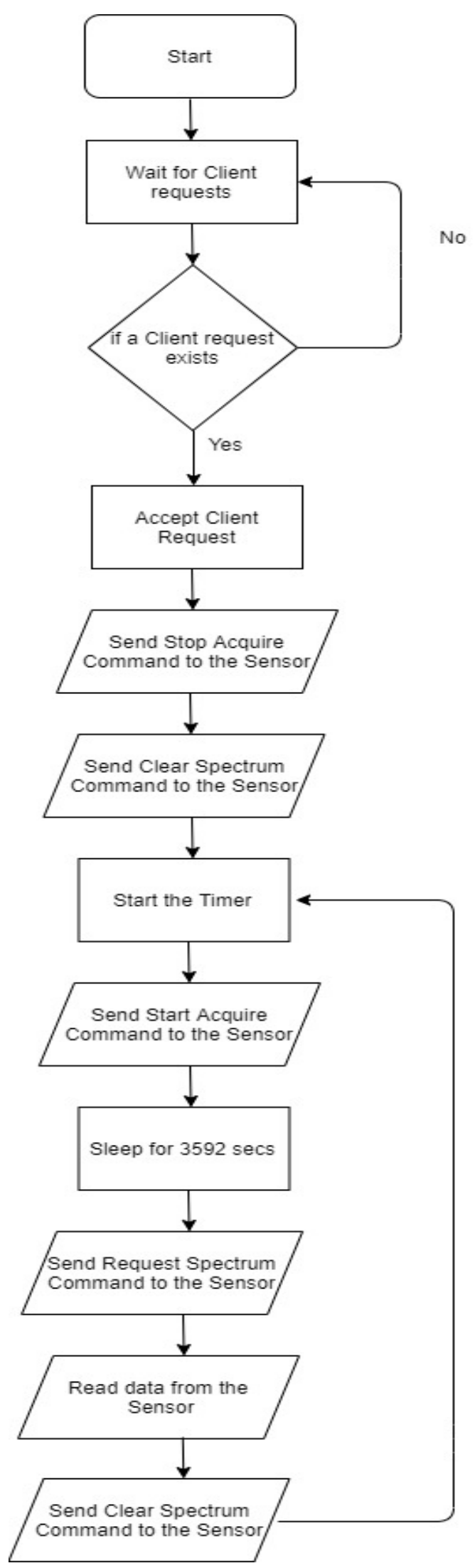

Figure 2. Flow chart of the developed algorithm. 


\subsection{Power Consumption}

As concerns the power consumption management issues, the power consumption of the cellular router is 157-170 mA@12 VDC (standby mode) and 310-485 mA@12VDC (communication mode). In order to minimize the power consumption, a timer circuit at the router's power supply module is optionally used. Thus, the router does not operate continuously (all the time), but for specific time periods. For instance, the router starts to operate for $4 \mathrm{~min}$ to initialize the connection and to perform appropriate controls and is switched off (or is in "sleep" mode) for the rest of the period of acquisition time (in our case $56 \mathrm{~min}$ ). The maximum current that can be drawn is $1 \mathrm{~A}$, limited by a corresponding npn transistor (which is responsible for the switching function).The maximum required current is $\sim 700 \mathrm{~mA}$. However, the circuit is interconnected with 1A fuse for safety reasons to avoid potential damage of the modules. The time period of $4 \mathrm{~min}$ is adequate for the router to start to operate and connect to the Internet and send the first commands of the sequential mode of operation. The router shuts down, after which it is switched off for the rest of the acquisition period; it restarts to support the server to collect the data through sockets. Following this, the server sends the second command list for the next acquisition.

\subsection{Database}

The design of the database of this application was performed using the MySQL database management system. A simplified algorithm was developed to load the data to a database named "MobileRadDB". This database is a table with 9 columns. The first column named "id" is the primary identification key with the "primary" and auto increment type and has a length of 20 characters. The second one, named "location", is the location of the measurement, which is a string of a length of 55 characters which cannot be null. The third column is named "instrument" and represents the name of the sensor used, followed by its serial number, which is a string of 55 characters which cannot be null. The fourth one is called "date_time" and represents the date and the time of measurement;it is of the MySQL "datetime" type and cannot be null. The fifth column contains the data of the measurement, is named "data", and is of the MySQL mediumblobtype which is actually a string of 1024 numbers separated by commas ","(comma separated values-csv). The sixth column is named "total_counts" and is the sum of all the counts of the measurement of float type.The seventh "K-40", eighth "Bi-214" and ninth "Tl-208" columns contain information about the concentration of the corresponding elements of the radioactivity sensors. There is also the composite key "DateLocationInstrument" which is unique for each measurement and is composed of the fields "date_time", location", "instrument". It imposes the constraint that two or more records with the same date-time, same location and same instrument cannot exist. From the time the data reach the server software, a record is created ina table named "radiomeasurements" in the MobileRadDB database. For instance, the record "AnavyssosGeoMAREA 8 February 2019 18:26:07 data 83876000 ", refers to the area of study "Anavyssos", to the sensor "GeoMAREA", to the measurement date "8 February 2019 ", to the time that the acquisition stopped "18:26:07" and to the measured gamma-ray spectrum (which is a string of 1024 numbers separated by commas), to the total counts "83786" and to the activity concentration after automated analysis of the aforementioned key radionuclides "Bi-214, K-40 and Tl-208".

\section{Results}

The GeoMAREA system was connected to the newly developed communication box to test the effectiveness of sensor integration as well as the communication between the sensor and computer system at the operational center. The system was deployed at the HCMR establishments, as well as at a close distance from the establishment on a building roof, to monitor radioactivity levels in a qualitative manner and to monitor the variability of different radioactive fallout due to rain and/or snow fall. The second monitoring period was during winter continued also at the dry period (from December 2020 to June 2021). Several tests and quality control exercises were performed before the operation of the system to test the 
functionality and effectiveness of the whole system in terms of data communication and power consumption (also during the winter period with limited sunlight), including the study of quality assurance of the sensor characteristics and its specifications.

Several events of rainfall were observed during the monitoring period. However, in this report, particular attention is paid to the unusual events of snowfall in the coastal area of the observation site. A typical background spectrum as well as the spectrum encountered during a snowfall is depicted in Figure 3.

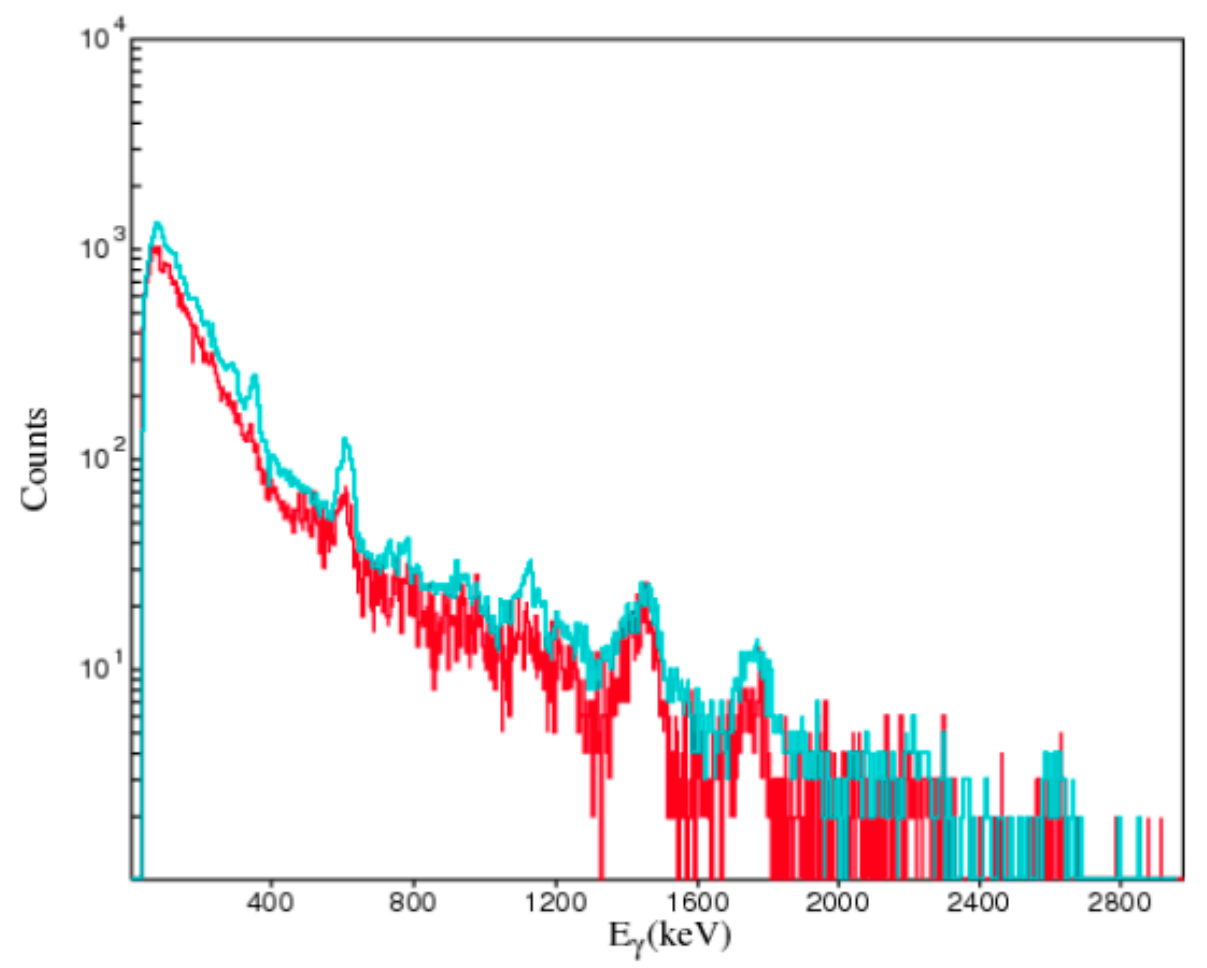

Figure 3. Typical spectra before and during snowfall as acquired from the GeoMAREA detection system. The background spectrum (without snowfall) is represented by the red line, and the foreground spectrum (during snowfall) by the green line. The time lag is $20 \mathrm{~min}$.

Quality control of the data was performed according to the lab-based spectra using reference sources. The time lag of the system was $20 \mathrm{~min}$. The gamma-ray spectra did not exhibit any loss of data during the pilot study. The data were only corrupted when the signal of the mobile telephony network was not strong enough to transmit the data to the operational center. In this case, some spikes were observed, and filtering processes were applied to subtract them from the spectra. When the signal of the mobile telephony network was absent, the solution to recover the spectra was to save the data in the data logger's internal memories. A rapid result of the system was the gross gamma-ray intensity rate (summing up all recorded counts divided by the time lag). The gross gamma ray intensity rate was increased by $\sim 40 \%$ at 16 February 2021 at 9:00 o/clock due to a snowfall event that lasted 1 day. According to the spectrum analysis the main contribution originated from the natural radionuclides of the ${ }^{238} \mathrm{U}$ and ${ }^{232} \mathrm{Th}$ daughters. The most obvious energy peaks are the radon and thoron progenies which are produced during the snowfall that is attached to the detector surface. Snow contains natural radionuclides, but it also has a high absorption capability used to attract particles in the atmosphere with a considerable activity concentration of natural radionuclides.

The red line spectrum is the background spectrum as acquired under normal weather conditions, while the green line represents the foreground spectrum as acquired from the GeoMAREA detection system during the snowfall. It is clearly seen in the spectrum that ${ }^{214} \mathrm{~Pb}$ and ${ }^{214} \mathrm{Bi}$ energy peak at 609 and $351 \mathrm{keV}$, respectively. Moreover, a slight peak at 
$2614 \mathrm{keV}$ of ${ }^{208} \mathrm{Tl}$ is also observed, as well as energy peaks at 911 and $968 \mathrm{keV}$ of ${ }^{228} \mathrm{Ac}$ $\left({ }^{228} \mathrm{Ra}\right.$ progeny). The automated software [24] provided only qualitative results for key radionuclides such as radon progenies $\left({ }^{214} \mathrm{Bi}\right.$ at 609 and $1764 \mathrm{keV},{ }^{214} \mathrm{~Pb}$ at $\left.351 \mathrm{keV}\right)$ and ${ }^{232} \mathrm{Th}$ progenies $\left({ }^{228} \mathrm{Ac}\right.$ at 911 and $968 \mathrm{keV},{ }^{208} \mathrm{Tl}$ at $\left.2614 \mathrm{keV}\right) \cdot{ }^{7} \mathrm{Be}$ and other cosmogenic radionuclides were not observed during the pilot study due to their low concentrations.

Such spectra as the above have been observed in the literature by in-situ detection systems indicating the main peaks of the radon daughters (as natural radionuclides enriched in rainwater and/or snow). During the second experimental period, the spectra were acquired in a time lag of $20 \mathrm{~min}$, and they exhibited excellent stability during wintertime. The recharge process of the battery pack through the solar module was very effective during the monitoring period since the saved power was adequate to operate the communication box (router and sensor) continuously. The analysis of the data was performed in an automated way using an upgrade of an existing software package [24]. The spectra were also analyzed using the software package SPECTRW [25]. The counts per seconds in key energy intervals (around $609 \mathrm{keV}$ ) were in agreement, having a bias between the two methods (automated and user selected) that varied from 4 to $12 \%$.

The acquired data are also depicted in counts per unit of time, called gross gamma-ray intensity rate of the measurement period. The time lag of the system was always the same. The aforementioned simplified analysis is depicted in Figure 4 in the period near to the snowfall event. It is very clear that the gross-ray intensity (total gamma-rays) increased by more than $20 \%$ before the event, after which there was a rapid drop in values reaching background levels after one day.

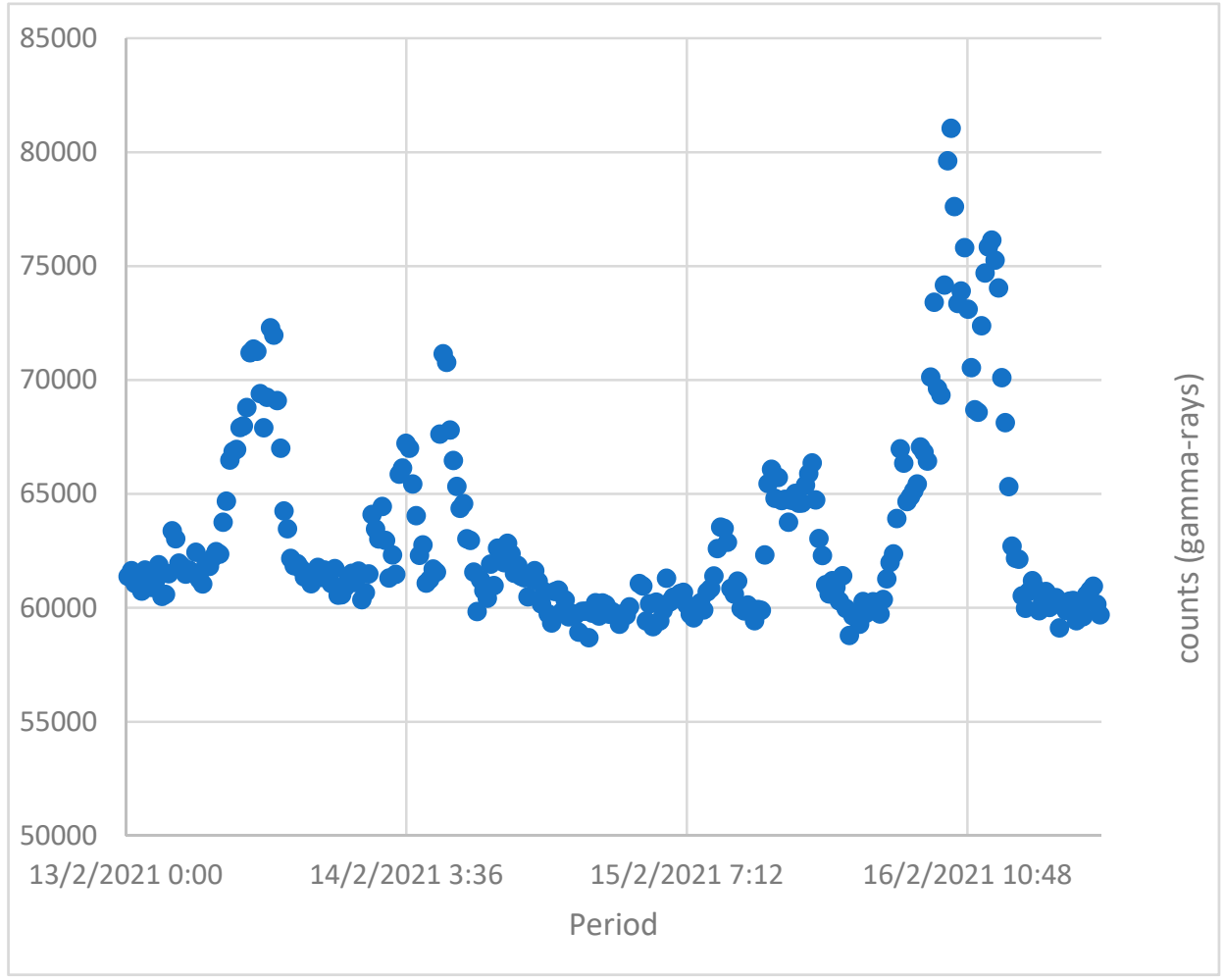

Figure 4. The gross gamma-ray intensity at the periods of rainfall and snowfall events.

According to the recorded gamma-ray intensity data and taking into account the time lag of the detection system, it can be clearly seen that snowfall is manifestly observed from the anomaly of the gross counts on 16 February 2021 at 10:48. The other two anomalies of gross counting rate represent rainfall events. Snowfall provided higher intensity compared to rainfall events mainly due to the remaining time of the snow on the surface of the detector. 


\section{Discussion}

The remote communication system is applied effectively for a long-term period by integrating a radioactivity marine sensor. As concerns the radioactivity measurement system, the system performance is improved by selecting as scintillator crystal a medium resolution spectrometer, to provide much better energy resolution of the acquired gammaray spectra compared to other radioactivity systems operated at sea $[13,22,26]$. The remote system enables a photovoltaic module that recharges the battery pack (having almost 1000 cycles in case deep discharge does not take place) providing power to the whole detection system continuously during the year. Due to the low consumption of the router as well as the low consumption of the detection device, the whole communication system provided data in a low sunlight period (from October 2020 to June 2021). Furthermore, the development and operation of the system proved to be cost effective (since the data transmission was almost EUR 10 per $10 \mathrm{~GB}$ per month). The combination of the low cost with the big data capacity was very helpful since the time lag of the measuring device could be reduced according to the experimental requirements and specifications. In the literature, several recent applications have been demonstrated where there are issues with limitation in capacity. The newly developed system was operated during a low sunlight period for about 8 months effectively and reliably. Some of the limitations of the developed communication system are that the operation exhibits practical difficulties when the intensity of the signal of the mobile telephony network was very low. In this case, the power consumption was increased, and loss of data could take place in the event of long-term cloudy weather.

The risks of the operation of the suggested communication system are related to the control of the data transmission and to the potential system damage (in case of exceptionally bad weather conditions). The first issue was solved by the application of quality control algorithms and the second risk could be reduced by integrating the system in fixed marine platforms for harsh environments and conditions. The benefits of applying this communication system are the low maintenance, since the system starts/stops remotely and frequent visits are thus not necessary; the low cost for getting (near) real-time data; the capability of the system to be integrated in buoys/fixed stations and mobile platforms; and the "plug and play" technology design. The perspectives of the application of the proposed communication system may include integrating market-available low-cost ocean sensors to operate at sea to assess the state of the marine environment. In future, the integration of the GPS sensor will be achieved by embedding the communication box in mobile platforms (e.g., marine drones, AUVs, gliders) to rapidly map radionuclides' concentration of aquatic areas near NPPs.

Furthermore, the application of the communication system would support the development of alarm and warning systems (including smart algorithms and decision support tools) to provide services to national and international authorities for civil protection by integrating the suggested system in existing marine networks of sensors. Such systems could also provide significant information about the radioactivity levels of fallout due to rainfall and snowfall by detecting the gamma-ray emitters of the artificial, natural, and cosmogenic radionuclides.

Author Contributions: Data curation, C.T.; Formal analysis, C.T.; Investigation, S.A. and C.T.; Methodology, S.A. and C.T; Software, S.A.; Supervision, C.T.; Validation, S.A.; Visualization, S.A.; Writing-Original draft, S.A. and C.T.; Writing-Review and editing, C.T. All authors have read and agreed to the published version of the manuscript.

Funding: This research was funded by national and EU funds under the National Strategic Reference Framework 2014-2020 in the framework of the project titled "Blue Growth with Innovation and application in the Greek Seas-GLAFKI" (MIS 5002438).

Institutional Review Board Statement: The study was conducted according to the KRIPIS project and approved for submission by the Institutional Director of the Institute of Oceanography (3 February 2021). 
Informed Consent Statement: Informed consent was obtained from all subjects involved in the study.

Data Availability Statement: The data are available on request. The data presented in this study are available on request to the corresponding author.

Acknowledgments: This work was supported by the KRIPIS project through the National Strategic Reference Framework (NSRF) 2014-2020 co-financed by Greece and the European Union (European Social Fund ESF). The authors would like to acknowledge the POSEIDON group for the continuous support and for the integration exercises of the sensor to the monitoring network system. The authors would also want to acknowledge the RadioMariners' group of HCMR for installation exercises as well as for the fruitful discussion during the analysis period.

Conflicts of Interest: There is no conflict of interest.

\section{References}

1. Chang, G.; Dickey, T.; Lewis, M. Toward a global ocean system for measurements of optical properties using remote sensing and in situ observations. In Remote Sensing of the Marine Environment; Gower, J., Ed.; ASPRS Publishing, 2006; Volume 6, pp. 285-326.

2. Frye, D.; LDetrick, F.R.; Collins, J.; Delaney, J.; Kelley, D.; LaBonte, A.; Brown, K. An acoustically linked moored-buoy ocean observatory. Eos Trans. Am. Geophys. Union 2006, 87, 213-218. [CrossRef]

3. IAEA 2020 Nuclear Technology Review 2020, GC(64)/INF/2, September 2020, IAEA/NTR/2020.

4. Buongiorno, J.; Jurewicz, J.; Golay, M.; Todreas, N. The Offshore Floating Nuclear Plant Concept. Nucl. Technol. 2016, 194, 1-14. [CrossRef]

5. IAEA. The Fukushima Daiichi Accident; IAEA: Vienna, Austria, 2015.

6. Schiermeier, Q. Radiation release will hit marine life. Nat. Cell Biol. 2011, 472, 145-146. [CrossRef]

7. Buesseler, K.O.; Jayne, S.R.; Fisher, N.S.; Rypina, I.I.; Baumann, H.; Baumann, Z.; Breier, C.F.; Douglass, E.M.; George, J.; Macdonald, A.M.; et al. Fukushima-derived radionuclides in the ocean and biota off Japan. Proc. Natl. Acad. Sci. USA 2012, 109, 5984-5988. [CrossRef] [PubMed]

8. Wada, T.; Nemoto, Y.; Shimamura, S.; Fujita, T.; Mizuno, T.; Sohtome, T.; Kamiyama, K.; Morita, T.; Igarashi, S. Effects of the nuclear disaster on marine products in Fukushima. J. Environ. Radioact. 2013, 124, 246-254. [CrossRef] [PubMed]

9. Smith, J.N.; Brown, R.M.; Williams, W.J.; Robert, M.; Nelson, R.; Moran, B. Arrival of the Fukushima radioactivity plume in North American continental waters. Proc. Natl. Acad. Sci. USA 2015, 112, 1310-1315. [CrossRef] [PubMed]

10. Okamura, H.; Ikeda, S.; Morita, T.; Eguchi, S. Risk assessment of radioisotope contamination for aquatic living resources in and around Japan. Proc. Natl. Acad. Sci. USA 2016, 113, 3838-3843. [CrossRef]

11. Till, J.E.; Grogan, H.A. (Eds.) Radiological Risk Assessment and Environmental Analysis; Oxford University Press: New York, NY, USA, 2008.

12. Tsabaris, C.; Tsiaras, K.; Eleftheriou, G.; Triantafyllou, G. 137Cs ocean distribution and fate at East Mediterranean Sea in case of a nuclear accident in Akkuyu Nuclear Power Plant. Prog. Nucl. Energy 2021, 139, 103879. [CrossRef]

13. Tsabaris, C.; Bagatelas, C.; Dakladas, T.; Papadopoulos, C.; Vlastou, R.; Chronis, G. An autonomous in situ detection system for radioactivity measurements in the marine environment. Appl. Radiat. Isot. 2008, 66, 1419-1426. [CrossRef]

14. Tsabaris, C.; Androulakaki, E.G.; Prospathopoulos, A.; Alexakis, S.; Eleftheriou, G.; Patiris, D.L.; Pappa, F.K.; Sarantakos, K.; Kokkoris, M.; Vlastou, R. Development and optimization of an underwater in-situ cerium bromide spectrometer for radioactivity measurements in the aquatic environment. J. Environ. Radioact. 2019, 204, 12-20. [CrossRef]

15. Androulakaki, E.; Tsabaris, C.; Eleftheriou, G.; Kokkoris, M.; Patiris, D.; Vlastou, R. Seabed radioactivity based on in situ measurements and Monte Carlo simulations. Appl. Radiat. Isot. 2015, 101, 83-92. [CrossRef] [PubMed]

16. Bagatelas, C.; Tsabaris, C.; Kokkoris, M.; Papadopoulos, C.T.; Vlastou, R. Determination of marine gamma activity and study of the minimum detectable activity (MDA) in 4pi geometry based on Monte Carlo simulation. Environ. Monit. Assess. 2009, 165, 159-168. [CrossRef] [PubMed]

17. Vlastou, R.; Ntziou, I.; Kokkoris, M.; Papadopoulos, C.; Tsabaris, C. Monte Carlo simulation of $\gamma$-ray spectra from natural radionuclides recorded by a NaI detector in the marine environment. Appl. Radiat. Isot. 2006, 64, 116-123. [CrossRef] [PubMed]

18. Androulakaki, E.; Tsabaris, C.; Eleftheriou, G.; Kokkoris, M.; Patiris, D.; Pappa, F.; Vlastou, R. Efficiency calibration for in situ $\gamma$-ray measurements on the seabed using Monte Carlo simulations: Application in two different marine environments. J. Environ. Radioact. 2016, 164, 47-59. [CrossRef]

19. Patiris, D.L.; Tsabaris, C.; Schmidt, M.; Karageorgis, A.P.; Prospathopoulos, A.M.; Alexakis, S.; Linke, P. Mobile underwater in situ gamma-ray spectroscopy to localize groundwater emanation from pockmarks in the Eckernförde bay, Germany. Appl. Radiat. Isot. 2018, 140, 305-313. [CrossRef] [PubMed]

20. Pensieri, S.; Patiris, D.; Alexakis, S.; Anagnostou, M.N.; Prospathopoulos, A.; Tsabaris, C.; Bozzano, R. Integration of Underwater Radioactivity and Acoustic Sensors into an Open Sea Near Real-Time Multi-Parametric Observation System. Sensors 2018, 18, 2737. [CrossRef] 
21. Tsabaris, C.; Scholten, J.; Karageorgis, A.P.; Comanducci, J.-F.; Georgopoulos, D.; Kwong, L.L.W.; Patiris, D.L.; Papathanassiou, E. Underwater in situ measurements of radionuclides in selected submarine groundwater springs, Mediterranean Sea. Radiat. Prot. Dosim. 2010, 142, 273-281. [CrossRef]

22. Tsabaris, C.; Anagnostou, M.; Patiris, D.; Nystuen, J.; Eleftheriou, G.; Dakladas, T.; Papadopoulos, A.; Prospathopoulos, A. A Marine Groundwater Spring in Stoupa, Greece: Shallow Water Instrumentation Comparing Radon and Ambient Sound with Discharge Rate. Procedia Earth Planet. Sci. 2011, 4, 3-9. [CrossRef]

23. Tsabaris, C.; Androulakaki, E.; Alexakis, S.; Patiris, D. An in-situ gamma-ray spectrometer for the deep ocean. Appl. Radiat. Isot. 2018, 142, 120-127. [CrossRef]

24. Tsabaris, C.; Prospathopoulos, A. Automated quantitative analysis of in-situ NaI measured spectra in the marine environ-ment using a wavelet-based smoothing technique. Appl. Radiat. Isot. 2011, 69, 1546-1553. [CrossRef]

25. Kalfas, C.; Axiotis, M.; Tsabaris, C. SPECTRW: A software package for nuclear and atomic spectroscopy. Nucl. Instrum. Methods Phys. Res. Sect. Accel. Spectrometers Detect. Assoc. Equip. 2016, 830, 265-274. [CrossRef]

26. Lee, S.; Lee, J.S.; Kim, H.S.; Park, J.; Baek, S.; Song, Y.; Seo, J.-M.; Kim, S.M. In-situ remotely controllable ocean radiation mon-itoring system. J. Instrum. 2020, 15, P06027. [CrossRef] 